\section{Case Reports in Ophthalmology}

Case Rep Ophthalmol 2020;11:423-429

DOI: 10.1159/000509262

Published online: August 6, 2020
(C) 2020 The Author(s)

Published by S. Karger AG, Basel www.karger.com/cop

\title{
Late Spontaneous Reabsorption of Interface Fluid after Descemet's Stripping Automated Endothelial Keratoplasty Surgery
}

\author{
Filippo Romanazzi Anna Morano Antonio Caccavale \\ Department of Ophthalmology, Abbiategrasso Hospital, ASST Ovest Milanese, \\ Abbiategrasso, Italy
}

\section{Keywords}

Descemet's stripping automated endothelial keratoplasty · Transient interface fluid · Interface opacity · Anterior segment optical coherence tomography · Delayed reabsorption .

Spontaneous reabsorption

\begin{abstract}
An 80-year-old male was referred to our hospital for chronic bullous keratopathy in the right eye. Ten years before, he was affected by an attack of primary acute angle closure glaucoma in high hyperopia and Fuchs' endothelial dystrophy. A bilateral iridotomy was performed. Thereafter, the patient developed an endothelial decompensation in the left eye, and, in another hospital, he underwent an open-sky combined cataract extraction and penetrating keratoplasty. Our surgical approach for the right eye consisted of phacoemulsification and, after 1 month, a Descemet's stripping automated endothelial keratoplasty (DSAEK). After the procedure, an interface fluid was suspected, and an anterior segment optical coherence tomography (OCT) confirmed it. The graft was well centered but thickened, showing no movement in the anterior chamber, adherent to the periphery of the recipient cornea but with a pool of fluid in the center. Seven days postoperatively, an anterior segment OCT showed initial signs of reabsorption of the fluid. On day 45 , the graft was adherent with normal thickness and the interface fluid had completely disappeared. The corneal stroma was clear, but a faint interface
\end{abstract}




\section{Case Reports in Ophthalmology}

opacity appeared and is still present. We obtained a good surgical result and best corrected visual acuity was $7 / 10$ at postoperative month 4 . No further surgical procedures are scheduled.

\section{Introduction}

Descemet's stripping automated endothelial keratoplasty (DSAEK) and Descemet's membrane endothelial keratoplasty (DMEK) [1] are treatments of choice for corneal endothelial dysfunction. The most common diseases for which these treatments are indicated are Fuchs' endothelial dystrophy and bullous keratopathy of various origin, in particular following cataract surgery.

Surgeons are confident with these surgical procedures, and use of lamellae supplied by eye banks [2] reduces the operation time and standardizes surgery. Nevertheless, complications are still possible, including pupillary blocks with increased pressure, detachment of the graft, graft rejections, and presence of transient interface fluid (TIF) [3]. Some of these complications can lead to the necessity of following surgical procedures.

\section{Case Report}

An 80-year-old male was referred to our hospital for chronic bullous keratopathy in the right eye with markedly impaired vision. Ten years before, he had an attack of primary acute angle closure glaucoma in high hyperopia and Fuchs' corneal dystrophy in this eye. He was hospitalized, and iridotomies were performed in both eyes. The attack resolved, and he reported a good visual acuity and no visual complaints for some years. One year ago, he complained of poor bilateral visual acuity and decided to consult an ophthalmologist.

The visit showed cataract and bullous keratopathy in both eyes. In another hospital, an open-sky combined cataract extraction and penetrating keratoplasty was performed in the left eye. After the patient was discharged, he was referred to us for the right eye.

A complete examination of the right eye revealed a visual acuity of $1 / 20$, ocular pressure of $12 \mathrm{~mm} \mathrm{Hg}$, bullous keratopathy, presence of dense cataract, narrow anterior chamber, and a floppy iris with a well-opened iridotomy at 11 o'clock.

In the left eye, best-corrected visual acuity was 6/10, ocular pressure $12 \mathrm{~mm} \mathrm{Hg}$, a clear corneal graft, an intraocular lens partially decentered, a floppy and dystrophic iris with a fixed asymmetric dilatated pupil, and the presence of the previous iridotomy at 1 o'clock.

For the right eye, also based on the experience with the previous surgery, our approach consisted of a 2-step surgery with removal of cataract with phacoemulsification first and then, after 1 month, with a DSAEK.

In spite of poor mydriasis, cataract surgery was performed after corneal disepithelization by an uncomplicated phacoemulsification with the implant of an intraocular lens in the capsular bag. The postoperative period was regular with the presence of moderate corneal edema and bullous keratopathy. After 1 month, we performed a DSAEK procedure. We used a pre-cut corneal graft of $110 \mu \mathrm{m}$ in thickness from our eye bank, and then we trephined a lamella of $8 \mathrm{~mm}$ in diameter. A standard DSAEK technique was performed. Postoperative hours after the surgery were regular, a digital tone demonstrated a relatively moderate to high pressure, the lamella was well centered and at a glance adherent to the recipient cornea with no movement of the graft, and there was no leakage from the surgical incisions. We started chloramphenicol- 


\section{Case Reports in Ophthalmology}

Case Rep Ophthalmol 2020;11:423-429

DOI: 10.1159/000509262

C 2020 The Author(s). Published by S. Karger AG, Basel www.karger.com/cop

Romanazzi et al.: Late Spontaneous Reabsorption of Interface Fluid after Descemet's Stripping Automated Endothelial Keratoplasty Surgery

betamethasone drops 5 times a day, and we added to the therapy a hyperosmotic drops sodium chloride $5 \%$ based 3 times a day to control the corneal edema. Later, on postoperative day 2, the lamella was still thick, and the recipient cornea appeared opaque with some folds; the intraocular pressure was $19 \mathrm{~mm} \mathrm{Hg}$. After a slit-lamp examination, a fluid interface was suspected. An anterior optical coherence tomography (OCT) was performed and confirmed the presence of a large amount of fluid in the center. Despite this finding, the lamella presented well centered, with no movement and adherent to the recipient cornea in the periphery on $360^{\circ}$.

The profile of the graft was less convex than that of the recipient cornea. The thickness of the lamella increased from the center to the periphery (Fig. 1). Some irregularities of the anterior and posterior surface of the lamella were also noticed. The recipient cornea was thick with some minor irregularities of the posterior surface (Fig. 2). Despite these unexpected and unpleasant findings, we decided to wait because the button was fixed and it did not show any movement or signs of dislocation. We continued the therapy with chloramphenicol-betamethasone drops 5 times a day and hyperosmotic drops sodium chloride $5 \%$ based. On postoperative day 7, the anterior segment at slit-lamp examination was slightly better with the recipient cornea being more transparent, an intraocular pressure of $16 \mathrm{~mm} \mathrm{Hg}$, and OCT showing initial signs of reabsorption of the fluid, starting in the peripheral part of the pocket (Fig. 3). A progressive resolution of the fluid was observed over the following days, and, after 45 days, the button was adherent to the recipient cornea and the interface fluid was completely reabsorbed (Fig. 4). In the meantime, the chloramphenicol-betamethasone drops were gradually reduced, and the hyperosmotic drops were stopped. At this time, the cornea was transparent and the graft thickness was markedly reduced and well centered. Despite this result, a faint interface opacity appeared.

\section{Discussion}

We treated a case of bullous keratopathy with a 2-step surgical approach, performing the phacoemulsification first and then a DSAEK. In this case, the phacoemulsification could have been burdened and potentially complicated by preexisting high hyperopia, narrow anterior chamber with a history of angle closure, poor dilation, and corneal edema with poor visualization.

We did not choose a single surgery in order not to prolong the surgical time due to the patient's advanced age and to avoid viscoelastic residues in the anterior chamber. After 1 month, we performed the second surgical step with a DSAEK.

Postoperative graft detachment is a well-described complication of DSAEK and depends on surgical experience (1.3-6.1\% of the procedures) and ocular preexisting conditions (medically treated glaucoma, previous trabeculectomy, previous aqueous shunt procedure, failed penetrating keratoplasty) $[4,5]$. It consists of a complete dislocation of the graft and needs surgical re-approach; very rarely, a spontaneous attachment of a partially detached donor corneal graft has been reported [6].

TIF is the presence of a pocket of fluid between the graft inserted and the recipient cornea. Sometimes, there is intraoperative evidence of TIF, and it can be observed using an intraoperative anterior segment OCT $[7,8]$, but its use is not standard yet. It is most common to identify TIF in the postoperative period, and probably this circumstance is underreported because the timing of postoperative anterior segment OCT is not standardized. When TIF occurs, some surgeons perform a reinjection of a bubble of air or gas in the anterior chamber, but 


\section{Case Reports in Ophthalmology}

Romanazzi et al.: Late Spontaneous Reabsorption of Interface Fluid after Descemet's Stripping Automated Endothelial Keratoplasty Surgery

spontaneous reabsorption of the fluid has been reported [7]. In our case, we noticed the fluid in the postoperative OCT, but we decided to wait because the lamella was fixed peripherally, well centered, and without signs of dislocations. The follow-up was characterized by a progressive reduction of the fluid and an overall improvement of the cornea despite the slow kinetics of reabsorption. When the lamella was adherent and TIF completely reabsorbed, the anterior segment OCT showed a complete restoration of the corneal anatomy. We also noted that the curve of the fluid reabsorption was not linear but progressed with a geometrical trend, with a progressively increasing curve from the beginning to the end of the process.

On day 45 , the corneal stroma was clear, but an interface opacity appeared. This phenomenon has previously been reported [9-13] and is linked to precipitated solutes in the interface, retained viscoelastic or lamellar irregularities caused by delayed adhesion, or uneven matching of lamellar fibrils. In our case, we supposed that the event was only caused by precipitated solutes because we did not use viscoelastic agents during the DSAEK.

\section{Conclusion}

In our case, we obtained a good surgical result with a 2-step approach of phacoemulsification and subsequent DSAEK. The long-standing presence of interface fluid between the recipient cornea and the endothelial lamella resolved spontaneously, and best corrected visual acuity was $7 / 10$ at postoperative month 4 . Some deposits at the interface are still present, and, in our opinion, the most important issue is that a delayed adhesion could present. In our case, the visual acuity recovery was quite good, and it was not necessary to schedule other surgical procedures.

\section{Acknowledgement}

The authors wish to thank Pavia - Eye Bank and its Director Dr. Roberto Ceccuzzi for technical support and collaboration.

\section{Statement of Ethics}

The authors have no ethical conflicts to disclose. Written informed consent was provided by the patient to have the case details and accompanying images published. The study was conducted in accordance with the Declaration of Helsinki.

\section{Conflict of Interest Statement}

The authors have no conflicts of interest to declare.

\section{Funding Sources}

No funding was received for this work. 


\section{Case Reports in Ophthalmology}

\begin{tabular}{l|l}
\hline DOI: $10.1159 / 000509262$ & (c) 2020 The Author(s). Published by S. Karger AG, Basel \\
\hline
\end{tabular}
www.karger.com/cop

Romanazzi et al: Late Spontaneous Reabsorption of Interface Fluid after Descemet's Stripping Automated Endothelial Keratoplasty Surgery

\section{Author Contributions}

F. Romanazzi, A. Caccavale: patient management and surgery. A. Morano: literature search. All authors contributed equally to the conception of the paper; writing, editing, and revision of the manuscript. All authors read and approved the final manuscript.

\section{References}

1 Anshu A, Price MO, Tan DT, Price FW Jr. Endothelial keratoplasty: a revolution in evolution. Surv Ophthalmol. 2012 May-Jun;57(3):236-52.

2 Terry MA, Shamie N, Chen ES, Phillips PM, Hoar KL, Friend DJ. Precut tissue for Descemet's stripping automated endothelial keratoplasty: vision, astigmatism, and endothelial survival. Ophthalmology. 2009 Feb;116(2):248-56.

3 Hurmeric V, Wang J, Kymionis GD, Yoo SH. Persistent lamellar interface fluid with clear cornea after Descemet stripping automated endothelial keratoplasty. Cornea. 2011 Dec;30(12):1485-7.

4 Nahum Y, Leon P, Mimouni M, Busin M. Factors Associated with Graft Detachment after Primary Descemet Stripping Automated Endothelial Keratoplasty. Cornea. 2017 Mar;36(3):265-8.

5 Lehman RE, Copeland LA, Stock EM, Fulcher SF. Graft Detachment Rate in DSEK/DSAEK after Same-Day Complete Air Removal. Cornea. 2015 Nov;34(11):1358-61.

6 Jastaneiah SS. Spontaneous attachment of detached donor-corneal graft following Descemet's stripping automated endothelial keratoplasty. Saudi J Ophthalmol. 2011 Jul;25(3):301-3.

7 Juthani VV, Goshe JM, Srivastava SK, Ehlers JP. Association between transient interface fluid on intraoperative OCT and textural interface opacity after DSAEK surgery in the PIONEER study. Cornea. 2014 Sep;33(9):887-92.

8 Hallahan KM, Cost B, Goshe JM, Dupps WJ Jr, Srivastava SK, Ehlers JP. Intraoperative Interface Fluid Dynamics and Clinical Outcomes for Intraoperative Optical Coherence Tomography-Assisted Descemet Stripping Automated Endothelial Keratoplasty From the PIONEER Study. Am J Ophthalmol. 2017 Jan;173:16-22.

9 Kim K, Alder B, Vora GK, Carlson AN, Afshari NA, Kuo AN, et al. Textural interface opacity after Descemetstripping automated endothelial keratoplasty. J Cataract Refract Surg. 2014 Sep;40(9):1514-20.

10 Vira S, Shih CY, Ragusa N, Sheyman A, Feder R, Weisenthal RW, et al. Textural interface opacity after Descemet stripping automated endothelial keratoplasty: a report of 30 cases and possible etiology. Cornea. 2013 May;32(5):e54-9.

11 Chhadva P, Cabot F, Ziebarth N, Kymionis GD, Yoo SH. Persistent corneal opacity after Descemet stripping automated endothelial keratoplasty suggesting inert material deposits into the interface. Cornea. 2013 Nov;32(11):1512-3.

12 Kymionis GD, Ide T, Yoo SH. Interface wavelike deposits after Descemet stripping automated endothelial keratoplasty. Arch Ophthalmol. 2009 Oct;127(10):1389-90.

13 Newman LR, Rosenwasser GO, Dubovy SR, Matthews JL. Clinicopathologic correlation of textural interface opacities in Descemet stripping automated endothelial keratoplasty: a case study. Cornea. 2014 Mar;33(3):306-9. 
Case Reports in Ophthalmology
Case Rep Ophthalmol 2020;11:423-429

DOI: $10.1159 / 000509262$

(c) 2020 The Author(s). Published by S. Karger AG, Basel www.karger.com/cop

Romanazzi et al.: Late Spontaneous Reabsorption of Interface Fluid after Descemet's Stripping Automated Endothelial Keratoplasty Surgery
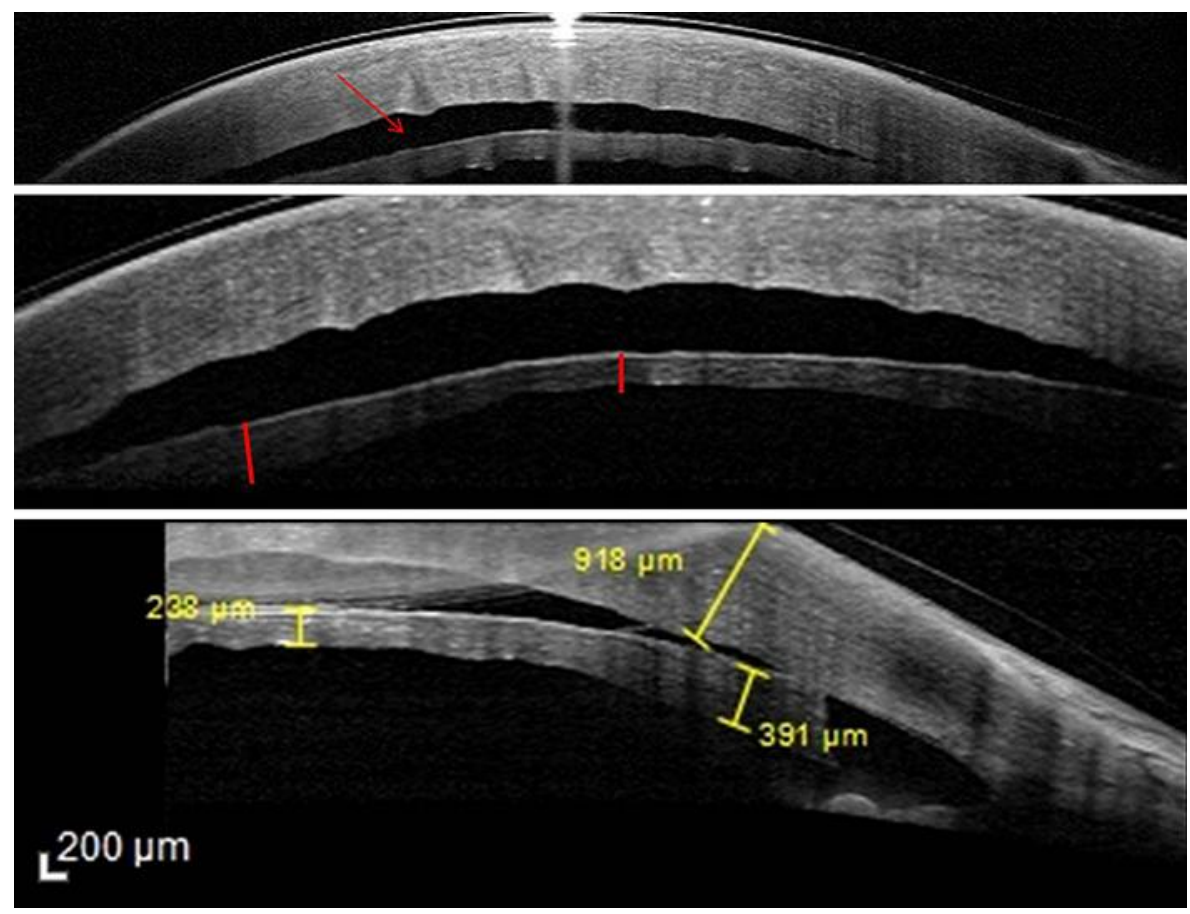

Fig. 1. Anterior segment OCT of the right eye on postoperative day 2: pocket of interface fluid and profile of the graft that was less convex than that of the recipient cornea. The thickness of the lamella increases from the center to the periphery.
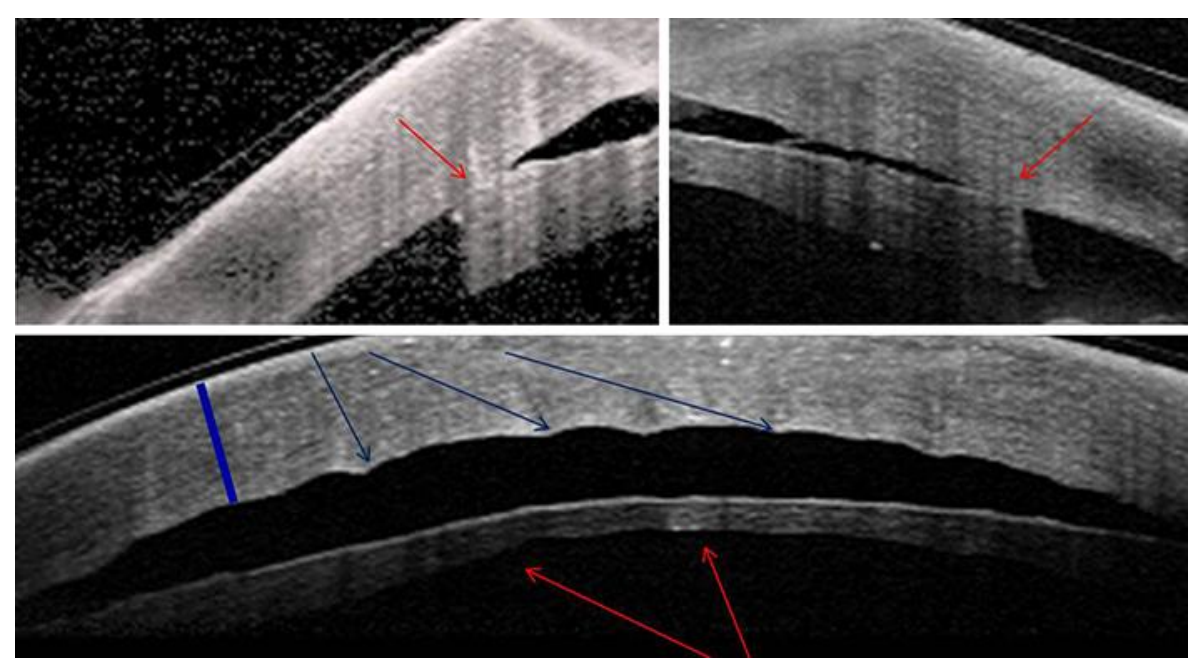

Fig. 2. Anterior segment OCT of the right eye on postoperative day 2: detail of the periphery and irregularities of the anterior and posterior surface of the lamella can be noted. The recipient cornea is irregular in the posterior surface and thickened. 


\section{Case Reports in Ophthalmology}

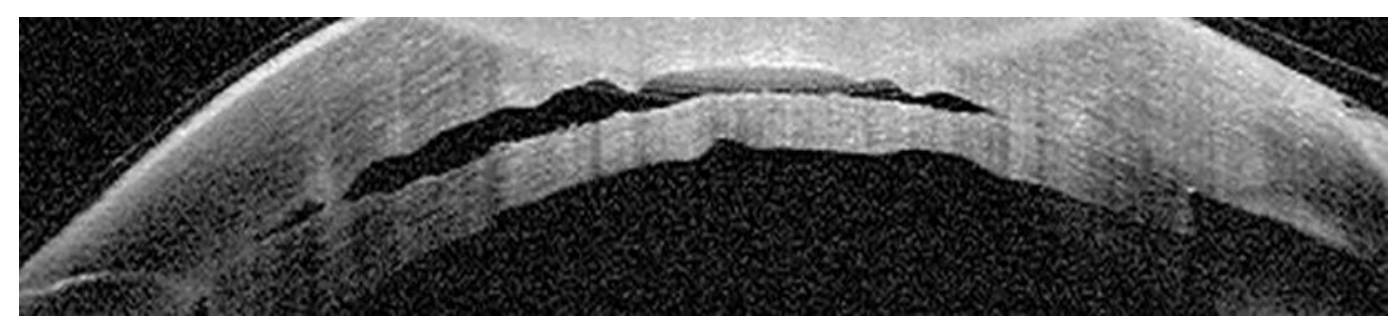

Fig. 3. Anterior segment OCT during follow-up: progressive reduction of interface fluid.
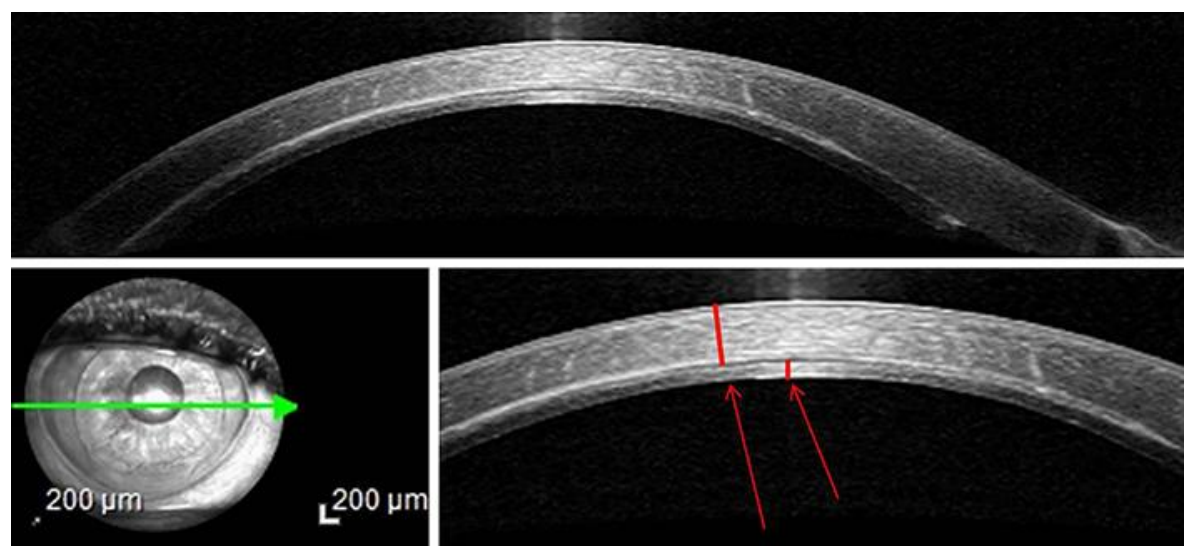

Fig. 4. Anterior segment OCT of the right eye on postoperative day 45: lamella is adherent and TIF completely reabsorbed. The recipient cornea and graft thickness are thin. Lamella thickness is regular from the center to the periphery. 